\title{
Influência da degradação do agregado na permeabilidade de lastros ferroviários
}

\author{
Influence of aggregate degradation on the \\ permeability of railway ballast
}

Larissa Rodrigues Dutra ${ }^{1}$, Rodrigo Pires Leandro ${ }^{2}$

\author{
${ }^{1,2}$ Laboratório de Pavimentação - LabPAV, Universidade Federal de Uberlândia, Uberlândia, MG, Brasil \\ e-mail: larissa.lrd@hotmail.com; rodrigo.leandro@ufu.br
}

\section{RESUMO}

A principal função da estrutura ferroviária é fornecer estabilidade e segurança para que o transporte opere de maneira eficiente. Os principais elementos constituintes dessa estrutura sobre o subleito são o sublastro, o lastro, os dormentes e os trilhos. O lastro é a camada granular que apresenta como funções fornecer estabilidade aos dormentes, a distribuição de esforços e a drenagem da superestrutura. Essa camada é posicionada entre os dormentes e o sublastro. No entanto, os esforços de impacto provocados pela passagem dos trens podem provocar a degradação do agregado, resultando na formação de finos prejudiciais à drenagem da via permanente. Uma drenagem ineficaz pode comprometer a resistência à deformação permanente das camadas geotécnicas resultando no aparecimento de defeitos na superestrutura como o deslocamento dos dormentes e o desnivelamento da via. Neste contexto, o objetivo principal deste trabalho foi avaliar a influência da degradação do lastro sobre sua capacidade drenante. O método experimental utilizado consistiu na degradação acelerada de amostras de basalto no tambor de abrasão Los Angeles, seguido pela avaliação da permeabilidade do material em cilindro de pequena dimensão. A relação entre os fenômenos de colmatação e permeabilidade do lastro limpo para o lastro altamente colmatado ficou evidenciada por meio dos resultados de laboratório. Verificou-se que a fração de agregado de $19,1 \mathrm{~mm}$ sofreu maior degradação, contribuindo para o acréscimo de finos no sistema, mostrando-se responsável pelo fenômeno de colmatação, representando elemento nocivo no que tange a drenagem do lastro ferroviário.

Palavras-chave: lastro ferroviário, degradação do agregado, colmatação, permeabilidade do lastro.

\begin{abstract}
The main function of the railway structure is to provide stability and security so that rail transport operates efficiently. Its main constituents on the subgrade are ballast, sub-ballast, sleepers and rails. The ballast is an element of the superstructure that is located between the sleepers and the sub-ballast. The main functions of the ballast are the stress distribution and the contribution to the drainage of the structure. However, the impact caused by the passage of the trains cause the degradation of the aggregate and produces fines that damages to the drainage of the structure. Ineffective drainage can lead to the appearance of defects in the superstructure such as the displacement of the sleepers and the unevenness of the railroad due to the occurrence of permanent deformations in the geotechnical layers. In this context, the objective of this work was to evaluate the degradation of the ballast and the way in which this phenomenon influences its draining capacity. For this, in a first step, characterization tests of the material were carried out. The experimental method consisted of the accelerated degradation of basalt samples in the abrasion Los Angeles drum. Then, the permeability evaluation of the material was performed. It was possible to verify the relation between the phenomena of fouling and permeability from the clean ballast to the highly fouled ballast. It was evidenced that the $19.1 \mathrm{~mm}$ aggregate fraction suffered greater degradation, contributing to the fines increase in the system, being responsible for the fouling phenomenon, representing a harmful element in relation to the drainage of the rail ballast.
\end{abstract}

Keywords: railway ballast, degradation of the aggregate, fouling, permeability of the ballast. 


\section{INTRODUÇÃO}

A rede ferroviária é parte fundamental de um sistema de transporte eficaz e desempenha papel vital na economia de um país [1]. Em relação ao desempenho da via férrea, este depende das características tecnológicas de todo o sistema, como interação veículo-via, tráfego, carga transportada, materiais e condições ambientais [2]. O propósito da estrutura ferroviária é fornecer estabilidade e segurança para que o transporte ferroviário funcione de maneira eficiente. Para atingir esse objetivo, a geometria da via deve ser mantida e cada componente da estrutura deve desempenhar suas funções de forma satisfatória, sob diferentes condições ambientais e operacionais [3]. Além disso, para ESVELD [2], a via férrea deve ser construída de tal forma que:

a) A passagem dos trens não provoque poluição ambiental excessiva, sob a forma de ruído e/ou vibrações do solo e;

b) O custo da vida útil total da via seja o menor possível, bem como a frequência de atividades de manutenção reduzida.

A principal função da via permanente é receber os impactos provocados pelas cargas das rodas, mantendo a resposta elástica dos materiais da estrutura [4]. Os principais elementos constituintes desse tipo de estrutura sobre o subleito são o sublastro, o lastro, os dormentes e os trilhos. De acordo com BRINA [5], o lastro é o elemento da superestrutura posicionado entre os dormentes e o sublastro. As principais funções do lastro são manter a estabilidade dos dormentes, distribuir as tensões de maneira atenuada para as camadas inferiores e facilitar a drenagem da superestrutura.

Para a efetiva drenagem da superestrutura é essencial que o material pétreo a ser utilizado apresente elevada resistência à degradação e elevada permeabilidade. No entanto, o impacto provocado pela passagem dos trens poderá provocar a degradação dos agregados, resultando na formação de finos prejudiciais à drenagem da via permanente.

Uma drenagem ineficaz pode levar ao aparecimento de defeitos na superestrutura como o deslocamento dos dormentes e o desnivelamento da via, em decorrência de deformações permanentes nas camadas geotécnicas. Como consequência, pode-se ter a redução da velocidade de operação dos trens e o aumento da probabilidade de acidentes nas vias.

Nas últimas décadas, estudos foram realizados relacionando a degradação acelerada de agregados para lastro ferroviário em máquina de abrasão Los Angeles e o desempenho dos pavimentos ferroviários. WENTY [6] realizou um estudo relacionando o ensaio de abrasão Los Angeles com a qualidade da geometria da via. Já SCHMIDT et al. [7] estudaram a permeabilidade de lastros ferroviários por meio de um aparato construído pela Universidade de Illinois denominado de UICHAP (University of Illinois Constant Head Aggregate Permeameter). Neste contexto, o propósito deste trabalho foi avaliar os efeitos da degradação do lastro ferroviário na drenabilidade da estrutura. Além disso, buscou-se obter a caracterização do agregado para fins de utilização em lastros ferroviários na região do Triângulo Mineiro.

\section{REVISÃO BIBLIOGRÁFICA}

\subsection{Degradação do agregado e a colmatação do lastro}

LEKARP et al. [8] entendem que "o esmagamento dos grãos é um processo progressivo, iniciando-se com tensões relativamente baixas e resultando em graduais alterações na estrutura granular e na densidade do material”. Em consonância a isto, WENTY [6] diz que o processo de degradação do agregado no lastro ferroviário se inicia com a quebra das arestas dos grãos, o que acaba por fornecer maior estabilidade ao lastro. Após este fenômeno, a abrasão provocada pelo tráfego e fatores externos aumentam a proporção de finos no lastro.

Para PIRES et al. [9], a interação natural entre os grãos do lastro cria pontos de contato entre eles. Além disso, a magnitude das tensões, a acumulação do tráfego e as ações de socaria (operação que tem o objetivo de compactar o lastro sob os dormentes) tendem a degradar os grãos, prejudicando o desempenho mecânico do lastro. Tal degradação acaba por gerar material fino que preenche os vazios entre os granulares, fenômeno conhecido como colmatação.

SELIG e WATERS [10] desenvolveram um estudo para identificar as fontes de materiais finos que colaboram para a colmatação do lastro. Constataram que a degradação do lastro é o principal fator que contribui para a geração de finos. O resultado da pesquisa está apresentado na Figura 1. 


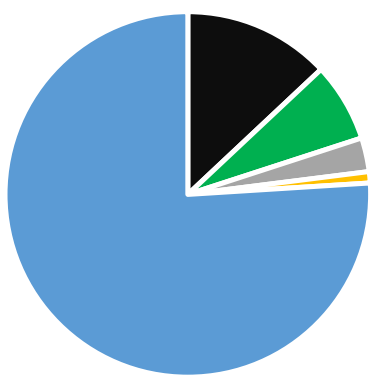

- Camada Granular Subjacente

- Superfície

$\square$ Subleito

- Dormente

- Lastro

Figura 1: Fontes de materiais finos em um lastro ferroviário. (Adaptado de SELIG e WATERS [10])

INDRARATNA e SALIM [11] consideram que vários fatores influenciam na degradação do lastro ferroviário como: amplitude, frequência e número de ciclos de carga, densidade, granulometria, angularidade e forma dos grãos. No entanto, o fator mais relevante para a quebra do material do lastro é a resistência à fratura de suas partículas. Quanto a isto, RAYMOND e DIYALJEE (1979 apud PIRES et al. [9]) afirmam que este processo pode ocorrer de três maneiras: quebra em aproximadamente duas partes iguais, quebra das projeções angulares e esmagamento/moagem de pequenas asperezas.

Devido à degradação do lastro, sua granulometria é alterada, ocorrendo também uma diminuição do índice de vazios da camada [9]. O material fino produzido, quando somado à entrada de água, pode ocasionar o surgimento de poropressões negativas (sucção), o que interfere negativamente na resistência e permeabilidade do lastro. SELIG e BOUCHER (1990 apud PIRES et al. [8]) defendem que testes de abrasão, como o ensaio de abrasão Los Angeles, são importantes para simular a degradação do lastro e fornecer uma base de avaliação quanto à adequabilidade do material.

Visando a quantificação da degradação e colmatação do lastro ferroviário, SELIG e WATERS [10] propuseram dois índices: Fouling Index (FI) e Percentage of Fouling Content (FC). O índice FI é a soma da porcentagem em massa de material passante na peneira de malha $4,75 \mathrm{~mm}\left(\mathrm{~N}^{\circ} 4\right)$ e passante na peneira de malha $0,075 \mathrm{~mm}$ ( $\mathrm{N}^{\circ} 200$ ). Já o índice FC é a relação entre a massa de material seco passante na peneira de malha $9,5 \mathrm{~mm}$ e a massa total seca da amostra [10]. Os autores ainda elaboraram uma tabela para classificar o grau de colmatação do lastro com base nos valores de FI (Tabela 1).

Tabela 1: Classificação do lastro de acordo com os valores de FI segundo SELIG e WATERS [10].

\begin{tabular}{c|c}
\hline CATEGORIA & FI (\%) \\
\hline Limpo & $<1$ \\
\hline Moderadamente limpo & $1 \mathrm{a}<10$ \\
\hline Moderadamente colmatado & $10 \mathrm{a}<20$ \\
\hline Colmatado & $20 \mathrm{a}<40$ \\
\hline Altamente colmatado & $\geq 40$ \\
\hline
\end{tabular}

Nos estudos conduzidos por WNEK et al. [12], utilizou-se o índice de abrasão Los Angeles (LAA) para avaliar a degradação e a durabilidade do agregado utilizado em lastros ferroviários. Este número fornece a porcentagem de desgaste por abrasão em relação ao peso inicial da amostra.

Ressalta-se que em um lastro altamente colmatado, as solicitações impostas pela passagem do material rodante alteram a resposta elástica do lastro [4]. Isso faz com que trilhos, fixações e dormentes tenham que suportar maiores níveis de tensão, gerando desgaste precoce dos componentes da via e comprometendo a trafegabilidade e segurança da ferrovia.

WNEK et al. [12] resumem ainda os três índices utilizados para avaliação da degradação do lastro em um único índice. Os autores formularam o Ballast Degradation Index (BDI) como uma média aritmética entre os índices FI, FC e LAA, onde um menor número indica um material mais durável. 


\subsection{Degradação do agregado e a permeabilidade do lastro ferroviário}

As partículas finas geradas pela abrasão dos agregados tendem a colmatar o lastro e reduzir seu desempenho na drenagem [13]. LIM [14] diz que a infiltração do sublastro na camada de lastro é maior na presença de água. Isso acontece devido à ação de bombeamento advinda do tráfego, que ocorre como consequência da reduzida permeabilidade do lastro. A presença de água também contribui para a formação de lama no subleito, a qual também será bombeada para o lastro sob a carga do tráfego.

SELIG e WATERS [10] documentaram o efeito do grau de colmatação do lastro em sua permeabilidade. A Tabela 2 mostra a variação da condutividade hidráulica do lastro conforme aumentam os valores de FI. É notável como a condutividade hidráulica é reduzida conforme o lastro varia de limpo para altamente colmatado.

Tabela 2: Análise da condutividade hidráulica conforme grau de colmatação do lastro. (Adaptado de SELIG e WATERS [10])

\begin{tabular}{|c|c|c|}
\hline \multirow{2}{*}{ CATEGORIA } & \multirow{2}{*}{ FI (\%) } & CONDUTIVIDADE HIDRÁULICA, $k_{h}$ \\
\hline & & $(\mathrm{mm} / \mathrm{sec})$ \\
\hline Limpo & $<1$ & $25-50$ \\
\hline Moderadamente limpo & $1-9$ & $2,5-25$ \\
\hline Moderadamente colmatado & $10-19$ & $1,5-2,5$ \\
\hline Colmatado & $20-39$ & $0,005-1,5$ \\
\hline Altamente colmatado & $>39$ & $<0,005$ \\
\hline
\end{tabular}

\section{MÉTODO EXPERIMENTAL}

\subsection{Coleta do material}

Para a realização deste trabalho foram coletados $100 \mathrm{~kg}$ de brita $0,100 \mathrm{~kg}$ de brita 1 e $400 \mathrm{~kg}$ de britas 2 e 3 . O material é de origem basáltica e foi coletado na cidade de Uberlândia (Figura 2). A composição da mistura de agregados foi elaborada em laboratório a partir do fracionamento peneira a peneira de modo a se obter a distribuição granulométrica de projeto.

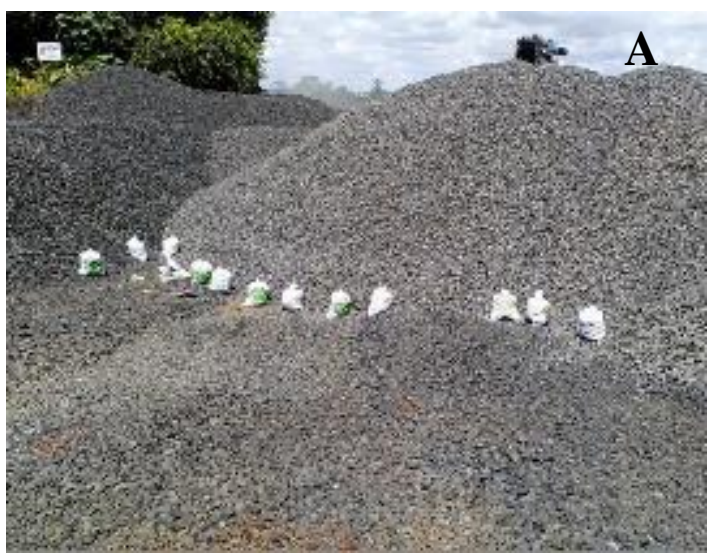

Figura 2: Coleta dos agregados diretamente das pilhas da pedreira localizada na cidade de Uberlândia.

\subsection{Ensaios de caracterização}

A análise em laboratório para caracterização dos agregados foi baseada nas normas da ASTM (American Society for Testing and Materials) e da ABNT (Associação Brasileira de Normas Técnicas). Os ensaios de caraterização realizados foram os de análise de distribuição granulométrica (ASTM C 136 [15]), Índice de Forma (ABNT NBR 5564 [16], Anexo A), Sanidade (ASTM C 88 [17]), Massa Específica Aparente (ASTM C 127 [18]), Absorção (ASTM C 127 [18]), Massa Unitária no Estado Solto (ABNT NBR NM 45 [19]) e abrasão Los Angeles (ASTM C 535 [20]). 


\subsection{Single particle crushing tests}

O ensaio de single particle crushing foi feito com base no trabalho apresentado por LIM [14]. Este experimento apresenta-se como forma de obter a resistência a tração do material que compõe o lastro através de uma compressão axial de cada partícula. Essa compressão, aplicada por duas placas planas e paralelas (Figura 3), gera tensões de tração internas às partículas levando-as à ruptura.

A preparação deste ensaio consistiu na secagem e peneiramento do material de forma a obter 20 partículas em cada uma das seguintes faixas granulométricas: $19-25 \mathrm{~mm}, 25-38,1 \mathrm{~mm}$ e 38,1-50mm. A máquina de compressão foi ajustada a uma taxa de carregamento constante de $1 \mathrm{~mm} / \mathrm{min}$, sendo este esforço aplicado até que a partícula se rompesse em dois ou mais pedaços ou até que o pó gerado pela compressão somasse aproximadamente $1 / 3$ do volume original da amostra. Durante o ensaio a força foi medida com uma precisão de $50 \mathrm{~N}$ e o deslocamento foi lido com uma precisão de $0,5 \mathrm{~mm}$. A tensão de tração de cada partícula foi determinada conforme a Equação 1.

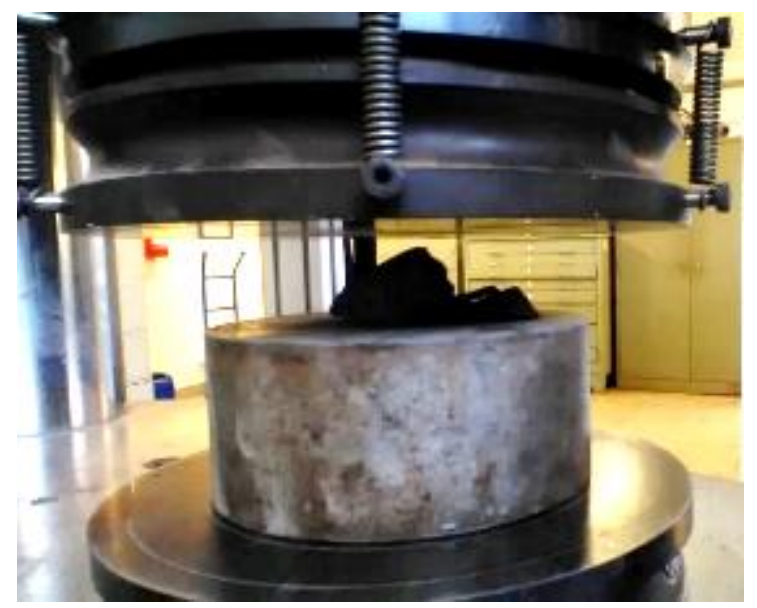

Figura 3: Placas planas e paralelas utilizadas no ensaio de Single Particle Crushing.

$$
\sigma_{f}=\frac{F_{f}}{d_{f}^{2}}
$$

Onde:

- $\sigma_{f}$ é a tensão de tração no momento da ruptura;

- $F_{f}$ é a força no momento da ruptura e;

- $d_{f}$ é o tamanho da partícula no momento da ruptura.

As tensões de tração obtidas para cada uma das faixas granulométricas foram organizadas em ordem crescente, permitindo dessa forma o cálculo da probabilidade de sobrevivência conforme proposto na Distribuição de Weibull (Equação 2).

$$
P_{s}=1-\frac{i}{(N+1)}
$$

\section{Onde:}

- $P_{S}$ é a probabilidade de sobrevivência;

- i é a posição da partícula em ordem crescente de tensão de tração e;

- $\mathrm{N}$ é o total de partículas.

A análise dos dados foi feita de acordo com o Módulo de Weibull, considerando a probabilidade de sobrevivência de uma partícula de tamanho d submetida a uma tensão $\sigma$ conforme a Equação 3 . 


$$
P_{s}(d)=\exp \left[-\left(\frac{\sigma}{\sigma_{0}}\right)^{m}\right]
$$

Onde:

- $P_{s}(d)$ é a probabilidade de sobrevivência de uma partícula de tamanho d;

- $\sigma_{0}$ é a tensão de tração em que $37 \%$ das partículas sobrevivem e;

- m é o Módulo de Weibull.

A relação entre o tamanho da partícula e a resistência do lastro pode ser obtida por meio do coeficiente angular da linha de tendência que melhor se adapta aos dados linearizados de acordo com as Equações 4 e 5 .

$$
\begin{aligned}
& y=\log \left(\sigma_{0}\right) \\
& x=\log \left(d_{f}\right)
\end{aligned}
$$

Onde:

- $d_{f}$ é o diâmetro final do agregado.

\subsection{Difração por raio $x$}

O ensaio de difração por raio $x$ foi realizado com base no trabalho apresentado por VIZCARRA [21]. De acordo com PETERSON (2008 apud VIZCARRA [21]) a difração de raios-x (DRX) é utilizada na determinação da composição mineralógica de uma amostra de pó de rocha $(<0,076 \mathrm{~mm})$ baseado nas ondas de raios-X refletidas.

A primeira etapa para realização deste experimento foi a obtenção da amostra de pó de basalto (Figura 4-A) por meio do peneiramento de pó de brita e pedrisco na peneira de abertura de malha de $0,075 \mathrm{~mm}$. A amostra foi então disposta no recipiente observado na Figura 4-B e o ensaio foi executado no difratômetro LabX XRD-6000. O difratômetro foi utilizado com radiação $\mathrm{CuK} \alpha(1,540 \AA$ ), sendo o ângulo $2 \theta$ analisado entre 5 e $90^{\circ}$ a um passo de $0,02^{\circ}$ com tempo de contagem igual a $2^{\circ}$ por minuto. A voltagem utilizada foi $40 \mathrm{kV}$ com uma corrente de $30 \mathrm{~mA}$.
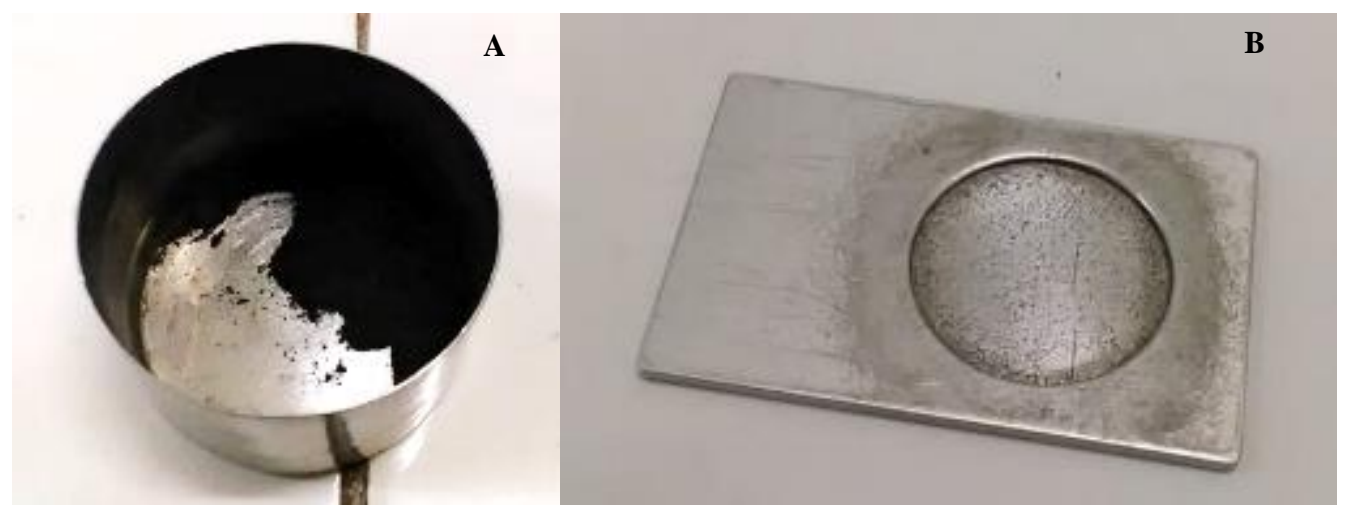

Figura 4: Preparação do ensaio A - amostra; B - recipiente para disposição da amostra.

\subsection{Degradação granulométrica por abrasão Los Angeles}

O primeiro passo para a realização do ensaio de degradação por abrasão Los Angeles foi a decalagem da curva granulométrica de projeto da amostra, a qual atende a faixa 4A da AREMA (Figura 5), de forma a atender aos requisitos dos aparelhos disponíveis para a execução do ensaio de permeabilidade. O permeâmetro utilizado permitia um diâmetro máximo do agregado de $19,1 \mathrm{~mm}$ e requeria uma amostra de $10 \mathrm{~kg}$. Logo, a curva granulométrica foi deslocada, fornecendo uma amostra com grãos menores e mais adequados para o ensaio conforme a Figura 5. 


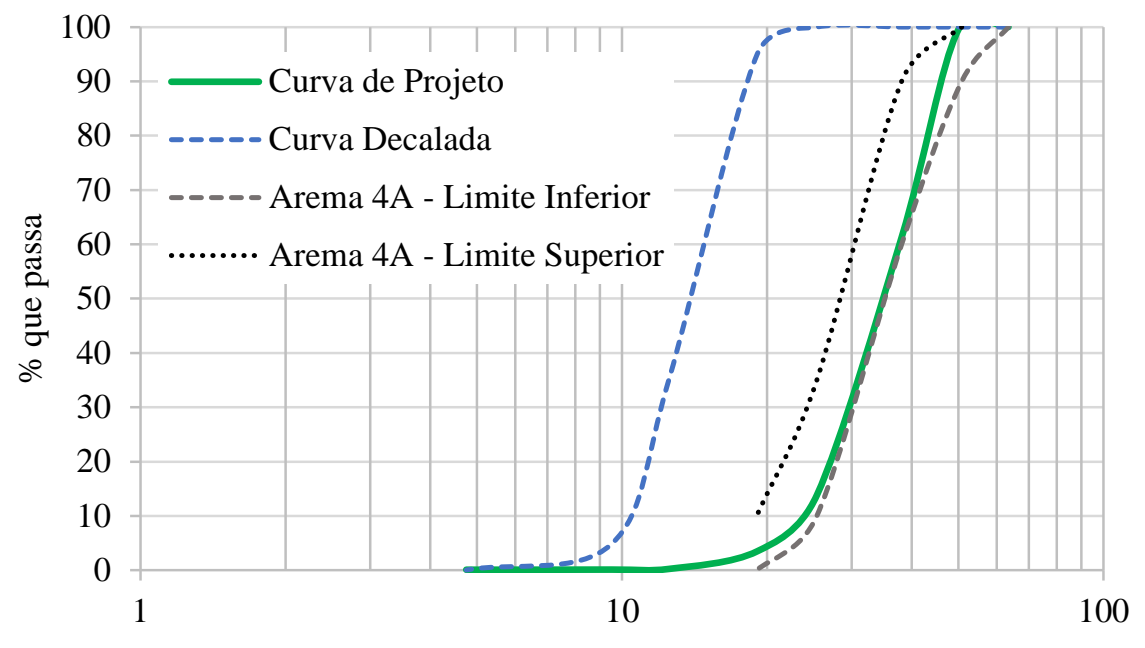

Abertura das peneiras (mm)

Figura 5: Decalagem da distribuição granulométrica de projeto e faixas granulométricas da AREMA.

Após a definição das quantidades necessárias em cada uma das frações de agregado, foi feito o peneiramento peneira a peneira das amostras para atingir a distribuição granulométrica da curva decalada. $\mathrm{O}$ ensaio de degradação foi realizado de modo a se obter quatro amostras em condições diferentes de colmatação segundo os índices FI como mostrado na Tabela 3.

Tabela 3: Características das amostras.

\begin{tabular}{c|c|c}
\hline AMOSTRA & FI (\%) & CLASSIFICAÇÃo \\
\hline 1 (referência) & $<1$ & Limpo \\
\hline 2 & $1 \mathrm{a}<10$ & Moderadamente limpo \\
\hline 3 & $20 \mathrm{a}<40$ & Colmatado \\
\hline 4 & $\geq 40$ & Altamente colmatado \\
\hline
\end{tabular}

Para atingir os índices FI desejados, as amostras foram degradadas no cilindro de abrasão Los Angeles por variadas quantidades de giros. A amostra 2 sofreu 250 rotações, a amostra 3 sofreu 1500 rotações e a amostra 4 passou por 2145 revoluções. Já a amostra 1 não foi degradada, sendo então tomada como referência. Vale destacar que o ensaio utilizou quatro amostras independentes, ou seja, não houve retorno de uma amostra já degradada para o tambor de abrasão Los Angeles.

\subsection{Avaliação da permeabilidade em cilindro de pequena dimensão}

$\mathrm{O}$ ensaio de avaliação da permeabilidade foi feito a partir de uma adaptação do experimento desenvolvido por SCHMIDT et al. [7]. Utilizou-se um permeâmetro com $9,96 \mathrm{~cm}$ de diâmetro e altura útil de $16,8 \mathrm{~cm}$. Para a realização deste experimento era importante que o dispositivo estivesse completamente vedado para que vazamentos de água não interferissem no resultado. Esta vedação foi feita utilizando borracha de vedação em ambas as extremidades do permeâmetro (Figuras 6-A e 6-B), além de fita veda rosca no local de conexão da mangueira. Além disso, foi utilizado um filtro na extremidade inferior do aparelho, o qual tinha a função de reter os finos das amostras impedindo que estes fossem eliminados com a passagem da água. As amostras foram levemente compactadas em cinco camadas iguais com a aplicação de dez golpes em cada uma delas (Figura 7). 


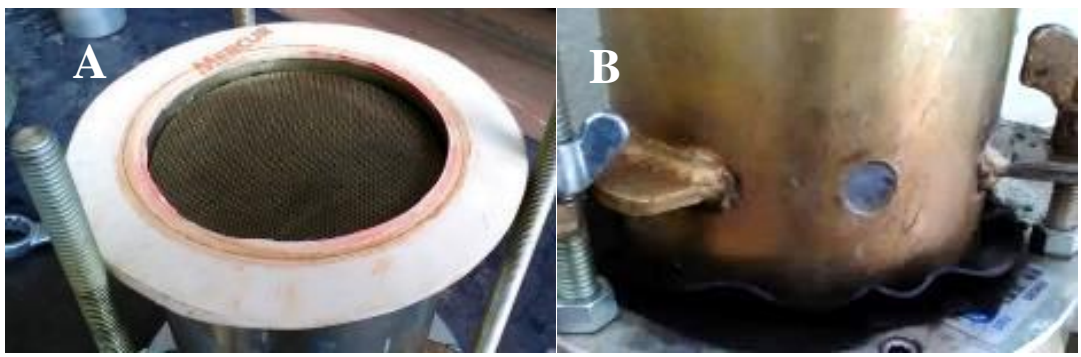

Figura 6: A -Borracha de vedação na extremidade superior; B -Borracha de vedação na extremidade inferior.

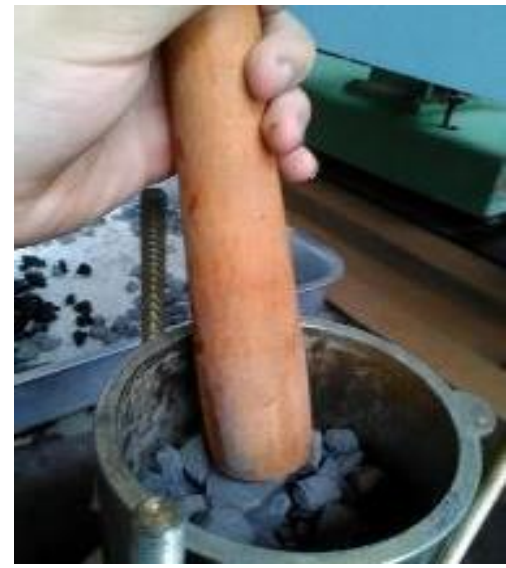

Figura 7: Compactação das camadas no permeâmetro.

Após o preparo do dispositivo e antes da colocação da amostra era necessário calibrar a vazão a ser utilizada. Em um primeiro momento, este valor foi obtido através da cronometragem do tempo necessário para encher uma proveta graduada de $500 \mathrm{ml}$. Em seguida, a mangueira foi conectada ao permeâmetro vazio, contendo apenas o filtro, para verificação da influência deste na vazão da água. Dessa forma, encontrou-se o valor que seria descontado na vazão final de cada amostra.

Depois do preenchimento do permeâmetro a mangueira era ligada na conexão inferior, gerando um fluxo ascendente, para garantir a saturação da amostra e a percolação da água nos vazios do agregado. Feito isso, a mangueira era conectada na extremidade superior e era cronometrado o tempo para encher a mesma proveta graduada de 500ml. Assim, foram obtidas as vazões do fluxo através das amostras 1, 2, 3 e 4 . De acordo com WILKINS (1956 apud SCHMIDT et al. [7]), a velocidade de descarga para materiais granulares de grandes dimensões é não linear e segue a Equação 6.

$$
V=C \times i^{n}
$$

Onde:

- V é a velocidade de descarga;

- C é uma constante empírica que depende da viscosidade do fluido e do raio hidráulico médio das partículas;

- i é o gradiente hidráulico e;

- n é um expoente empírico, obtido por regressão não linear.

\section{RESULTADOS E DISCUSSÃO}

\subsection{Ensaios de caracterização}

Os resultados obtidos a partir dos ensaios de caracterização estão resumidos na Tabela 4. Os índices FI e FC indicam que o material, antes do ensaio, poderia ser classificado como lastro limpo. Em relação ao índice de forma, infere-se que a forma média do agregado está de acordo com as recomendações dispostas na ABNT 
NBR 5564 [16], ou seja, forma cúbica. No entanto, a quantidade de partículas não cúbicas (17\%) ultrapassa o limite recomendado pela norma $(15 \%)$.

Os resultados referentes ao ensaio de sanidade demonstram que a porcentagem total de perda (5\%) está dentro do limite de 10\% estabelecido pela ABNT NBR 5564 [16]. Pode-se, portanto, considerar o material ensaiado adequado quanto à resistência a intempéries (sanidade). No tocante à massa unitária no estado solto, o resultado de $1450 \mathrm{kgf} / \mathrm{m}^{3}$ atende ao requisito da ABNT NBR 5564 [16], cujo valor mínimo é de $1250 \mathrm{kgf} / \mathrm{m}^{3}$. Quanto à massa específica aparente de $2190 \mathrm{kgf} / \mathrm{m}^{3}$ este é menor que o limite especificado de $2500 \mathrm{kgf} / \mathrm{m}^{3}$ [16]. Do mesmo modo, a absorção de $0,90 \%$ é superior ao limite definido pela ABNT NBR 5564 [16] de $0,80 \%$.

Tabela 4: Resultados dos ensaios de caracterização dos agregados virgens (sem degradação).

\begin{tabular}{c|c}
\hline TIPO DE ENSAIO & RESULTADO \\
\hline Análise Granulométrica & F, $04 \%$ de material pulverulento $=0,127 \%$ \\
& FC $=0,118 \%$ \\
\hline Índice de Forma & Forma média cúbica \\
\hline Sanidade & $17 \%$ de partículas não cúbicas \\
\hline Massa Específica Aparente & $5 \%$ de perda \\
\hline Absorção & $2190 \mathrm{kgf} / \mathrm{m}^{3}$ \\
\hline Massa Unitária no Estado Solto & $0,90 \%$ \\
\hline Abrasão Los Angeles & $1450 \mathrm{kgf} / \mathrm{m}^{3}$ \\
\hline
\end{tabular}

Em relação ao índice de abrasão Los Angeles (LAA), o limite máximo na ABNT NBR 5564 [16] é de $30 \%$. Assim, o resultado obtido (11\%) indica baixa degradação do material, apesar deste apresentar absorção acima do limite normativo. A realização deste ensaio permitiu ainda uma análise visual dos grãos (Figura 8), a partir da qual constatou-se a quebra das arestas das partículas. Essa quebra de angularidades acaba por gerar frações menores, tornando os grãos mais lisos e arredondados, e contribuindo para a colmatação do lastro.

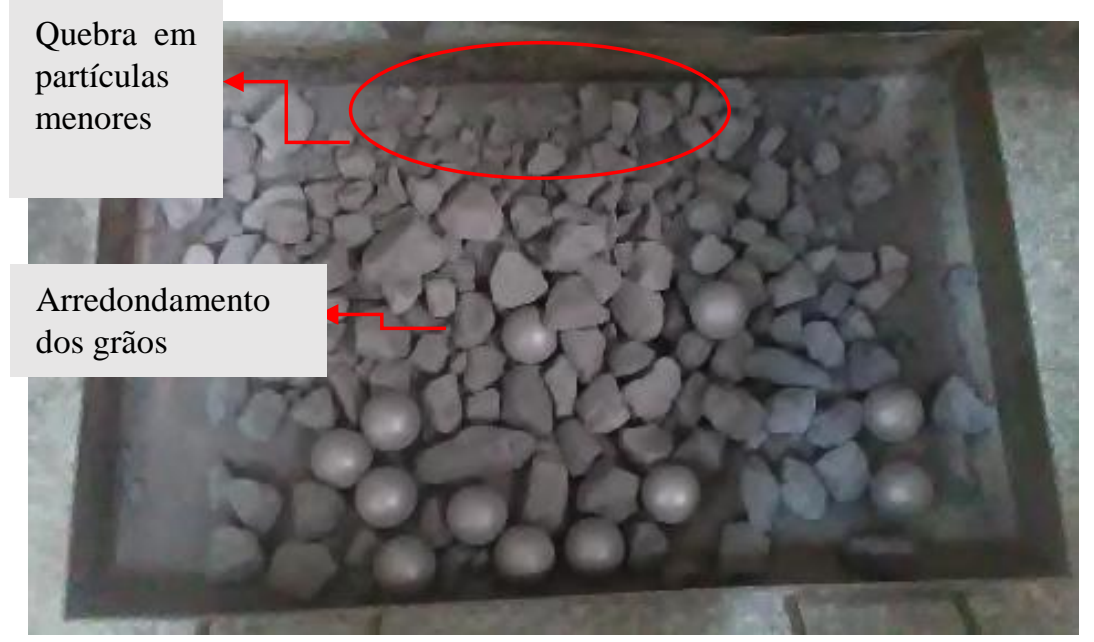

Figura 8: Análise visual do material após ensaio de abrasão Los Angeles.

\subsection{Single Particle Crushing Tests}

Os valores de $\sigma o$ e $m$ podem ser determinados por meio de um gráfico onde as ordenadas e as abcissas são obtidas por linearizações. A partir deste gráfico, tem-se que o Módulo de Weibull é o coeficiente angular da linha de tendência que melhor se ajusta aos dados e o valor de $\sigma o$ é aquele em que $y=0$. A Figura 9 mostra 
um exemplo para a determinação do Módulo de Weibull para a fração granulométrica entre as peneiras de abertura de malha de 19 a 25mm, sendo que na Tabela 5 são apresentados os resultados para todas as frações. Já na Figura 10 é apresentada a relação entre o tamanho e a resistência das partículas.

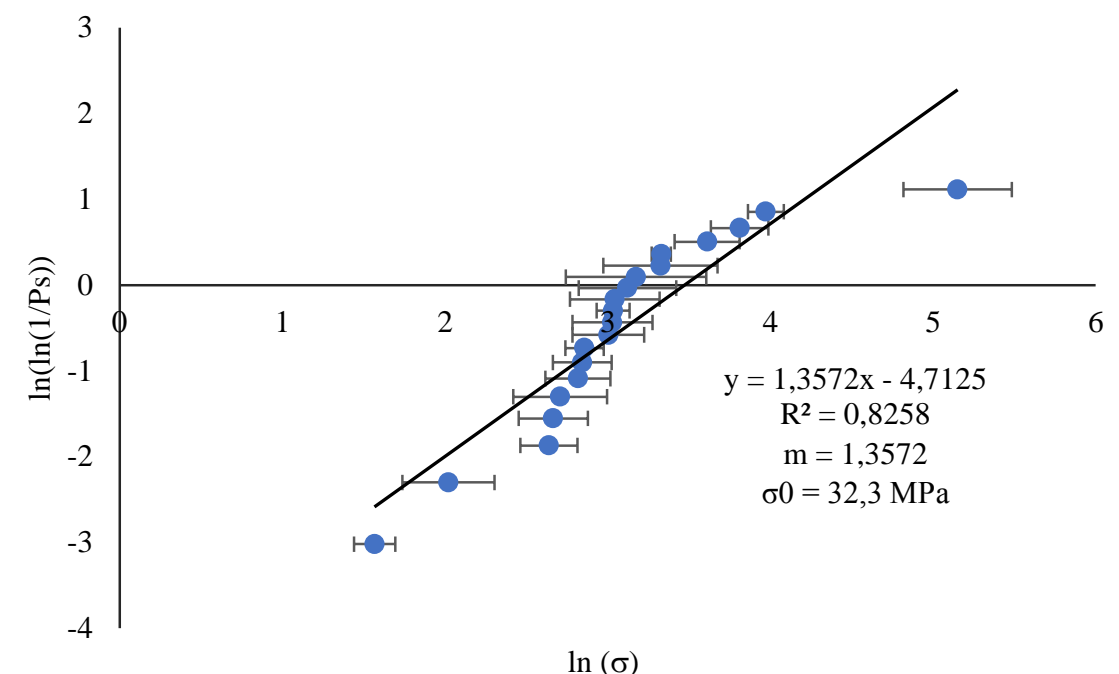

Figura 9: Relação entre a probabilidade de sobrevivência e a tensão de tração de ruptura para a fração de 19 a $25 \mathrm{~mm}$

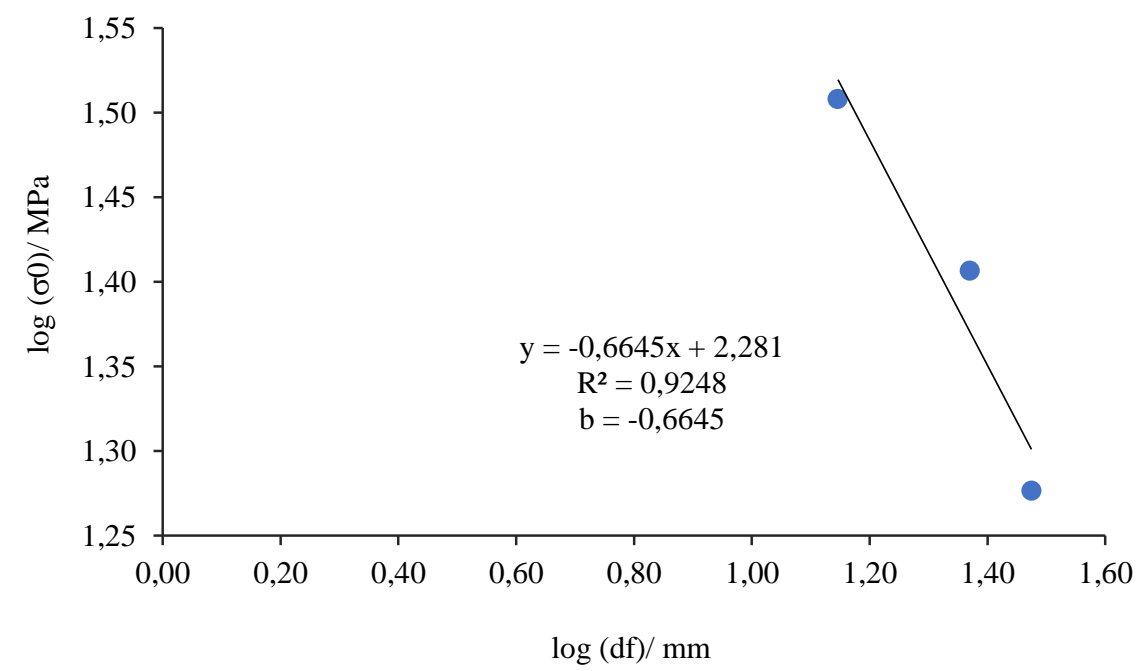

Figura 10: Relação entre o diâmetro final da partícula e a tensão de tração.

Tabela 5: Resumo dos resultados de Single Particle Crushing.

\begin{tabular}{c|c|c|c}
\hline FRAÇÃO GRANULOMÉTRICA (mm) & $\mathbf{\sigma 0}(\mathbf{M P a})$ & $\mathbf{d f}(\mathbf{m m})$ & $\mathbf{R}^{\mathbf{2}}$ \\
\hline$\# 38,1-\# 50$ & 18,9 & 29,8 & 0,94 \\
\hline$\# 25-\# 38,1$ & 25,5 & 23,4 & 0,90 \\
\hline$\# 19-\# 25$ & 32,2 & 14,0 & 0,83 \\
\hline
\end{tabular}

A partir da análise da Tabela 5 percebe-se que quanto menor o grão, maior a sua resistência. Este fenômeno ocorre devido a menor área de contato para aplicação da carga podendo estar associado também a maior probabilidade de falhas internas em fragmentos de maior dimensão. Além disso, nota-se pela Figura 10 que, para o material analisado, a influência do tamanho dos grãos na resistência do lastro é considerável, da- 
do o coeficiente b $(-0,6645)$ ser superior a 0,5 em módulo.

Nota-se, ainda pela Tabela 5, que a linha de tendência linear representa melhor o comportamento das partículas maiores, conforme mostra a variação do coeficiente $\mathrm{R}^{2}$. A dispersão dos resultados ocorreu devido a variação da forma de cada um dos grãos analisados.

\subsection{Difração por raio $x$}

Na Figura 11 é mostrado o resultado do ensaio de difração por raio $\mathrm{x}$ onde tem-se a intensidade da luz difratada conforme a variação do ângulo $2 \theta$. O gráfico obtido foi comparado com aqueles disponíveis no catálogo do ICSD [22], analisando os elementos cuja presença era esperada no basalto.

A partir da análise da Figura 11 percebe-se quantidade destacada de Anortita (CaAl2Si2O8), analisada conforme a base de estrutura cristalina de número 654 no catálogo do ICSD [22] (Inorganic Crystal Structure Database). Além disso, constata-se também a presença de Albita ( NaAlSi3O 8 - analisado conforme a base de número 9829) e quartzo (SiO2 - analisado conforme a base de número 27745).

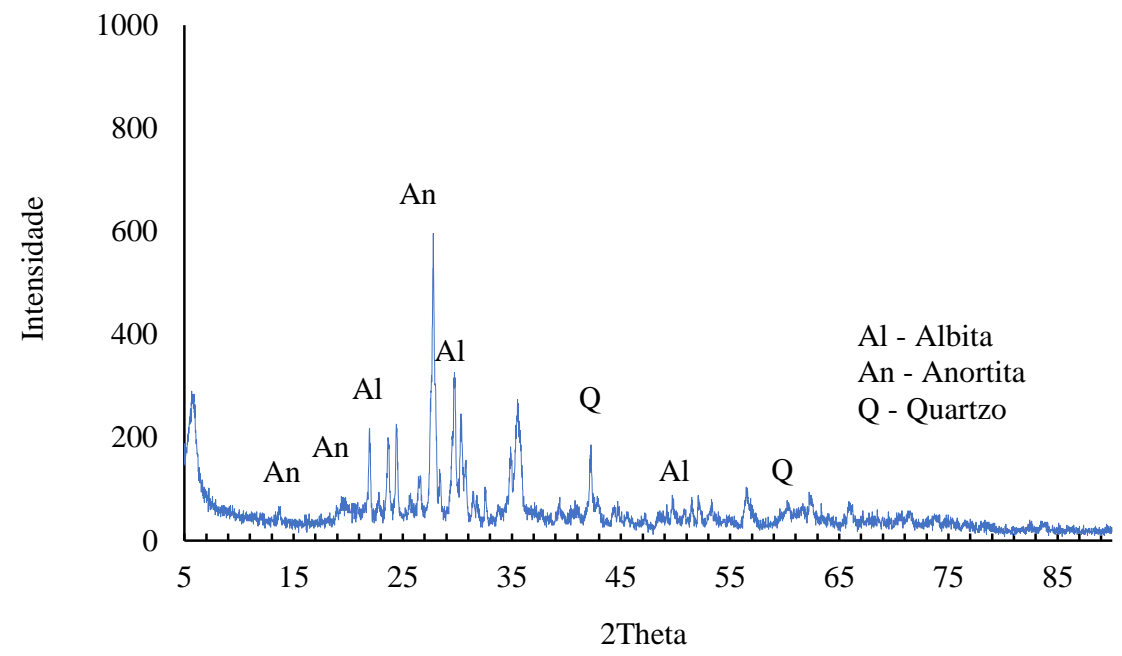

Figura 11: Resultado do ensaio de difração por raio x para o basalto.

A Anortita e a Albita pertencem ao grupo de minerais feldspáticos chamado de plagioclásio. Este grupo de minerais constitui uma série isomórfica completa, variando desde o termo mais sódico (albita-NaAlSi3O8) até o mais cálcico (anortita-CaAl2Si2O8). Ambos apresentam dureza variando de 6 a 6,5, o que contribui para a resistência da rocha basáltica utilizada em lastros. A presença de quartzo também contribui para esta característica já que ele é classificado como o quarto material mais duro de acordo com a escala de Mohs. A partir dos resultados de abrasão Los Angeles e da identificação mineralógica dos componentes, estima-se, segundo critério de RAYMOND [23], uma classificação de nível 1 a 2 dos agregados desse trabalho, indicando elevada qualidade desses materiais para utilização em lastros de vias permanentes.

\subsection{Degradação granulométrica por abrasão Los Angeles}

Após a degradação das amostras, determinaram-se as distribuições granulométricas resultantes e que podem ser vistas na Figura 12. Além disso, foram obtidos os índices FI, FC, LAA e BDI para cada uma das amostras e que são mostrados na Tabela 6.

Analisando-se a Figura 12 percebe-se o deslocamento da curva granulométrica, caracterizando a redução dos grãos das amostras e o acréscimo de finos, o que condiz com o aumento do índice FI que caracteriza o grau de colmatação do lastro. Pela análise da Tabela 6 nota-se que mesmo que a degradação tenha atingido altos níveis, chegando inclusive a valores de lastro altamente colmatado, em nenhuma amostra foi verificada a redução do diâmetro máximo do agregado. Tal fato permite afirmar que os grãos da fração $19,1 \mathrm{~mm}$ não foram totalmente reduzidos, restando alguns grãos desgastados e arredondados. 


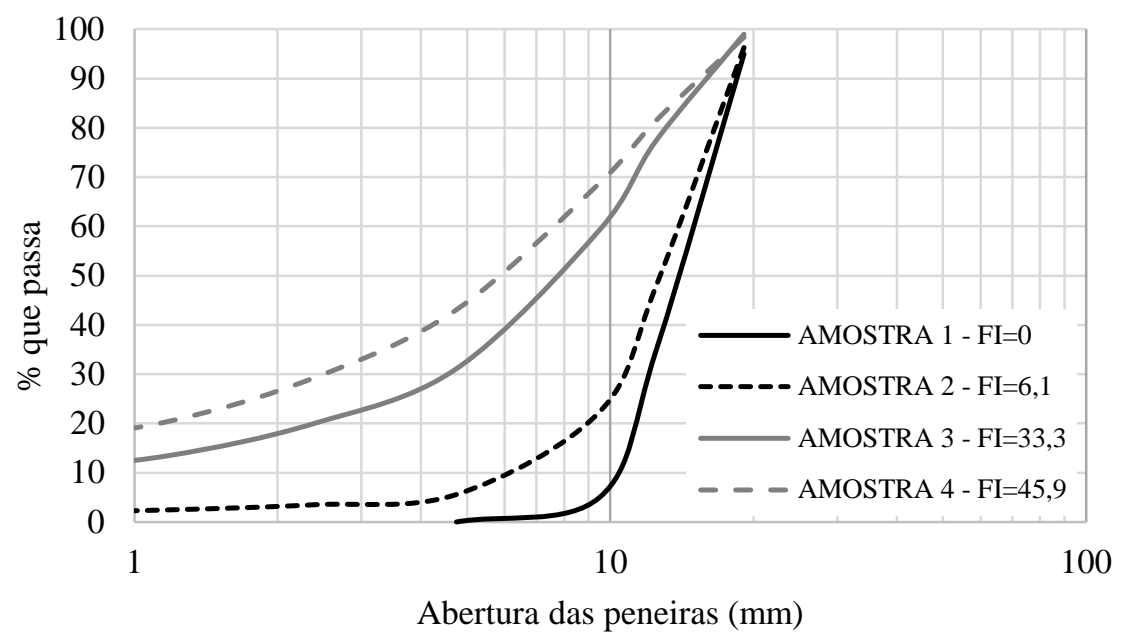

Figura 12: Curvas granulométricas após a degradação por abrasão Los Angeles.

Tabela 6: Resumo dos índices obtidos para cada uma das amostras degradadas.

\begin{tabular}{c|c|c|c|c|c}
\hline AMOSTRA & DMÁX (mm) & FI (\%) & FC (\%) & LAA & BDI \\
\hline 1 (referência) & 19,1 & 0 & 5,00 & 0,00 & 1,67 \\
\hline 2 & 19,1 & 6,13 & 22,36 & 2,97 & 10,49 \\
\hline 3 & 19,1 & 33,30 & 59,31 & 15,58 & 36,06 \\
\hline 4 & 19,1 & 45,89 & 68,81 & 22,45 & 45,72 \\
\hline
\end{tabular}

Para melhor visualização do fenômeno de degradação e o acréscimo de finos, foi feita uma análise visual das partículas após abrasão, a qual pode ser verificada na Figura 13. Percebe-se o aumento considerável da quantidade de finos, além da confirmação de que os grãos da fração de $19,1 \mathrm{~mm}$ sofreram redução, no tamanho e em quantidade, ficando com a superfície mais lisa e arredondada. Na Tabela 7 são apresentadas as porcentagens de degradação para cada peneira, de cada uma das amostras, em relação à amostra 1 (referência).

Tabela 7: Porcentagens de degradação em relação à amostra 1.

\begin{tabular}{c|c|c|c|c|c|c|c}
\hline \multirow{2}{*}{$\begin{array}{c}\text { PENEIRA } \\
(\mathbf{m m})\end{array}$} & \multirow{2}{*}{$\begin{array}{c}\text { AMOSTRA 1 } \\
\mathbf{( g )}\end{array}$} & \multicolumn{2}{|c|}{ AMOSTRA 2 } & \multicolumn{2}{c|}{ AMOSTRA 3 } & \multicolumn{2}{c}{ AMOSTRA 4 } \\
\cline { 3 - 7 } & $\mathbf{( g )}$ & $\mathbf{( \% )}$ & $\mathbf{( g )}$ & $\mathbf{( \% )}$ & $\mathbf{( g )}$ & $\mathbf{( \% )}$ \\
\hline 19,1 & 502 & 368,3 & $-26,63$ & 96,3 & $-80,82$ & 156,5 & $-68,82$ \\
\hline 12,5 & 6004,4 & 4801,3 & $-20,04$ & 2102,6 & $-64,98$ & 1642,9 & $-72,64$ \\
\hline 9,5 & 3000,5 & 2555 & $-14,85$ & 1772,7 & $-40,92$ & 1240,6 & $-58,65$ \\
\hline 4,75 & 500,9 & 1670,4 & 233,48 & 2753,5 & 449,71 & 2508,2 & 400,74 \\
\hline
\end{tabular}

Analisando a Tabela 7 percebe-se que a fração de 19,1mm sofreu maior nível de degradação para as condições características de lastros moderadamente limpos (amostra 2) e colmatados (amostra 3), seguida pela fração de $12,5 \mathrm{~mm}$. Por outro lado, a fração de 4,75mm apresentou um acréscimo superior a $230 \% \mathrm{em}$ massa para todas as situações. Assim, pode-se inferir que as frações de maior dimensão, principalmente a fração de 19,1 mm, sofreram maior grau de degradação, contribuindo para o aumento da fração de $4,75 \mathrm{~mm}$. 


\begin{tabular}{|c|c|c|c|c|}
\hline \multirow{2}{*}{ Tamanho de Malha da Peneira (mm) } & \multicolumn{4}{|c|}{ Número de Rotações } \\
\hline & 0 & 250 & 1500 & 2145 \\
\hline 19,1 & & & & \\
\hline 9,5 & & & & \\
\hline 4,75 & & & & \\
\hline 2,38 & & & & \\
\hline 1,18 & & & & \\
\hline 0,6 & & & & \\
\hline 0,3 & & & & \\
\hline 0,15 & & & & \\
\hline 0,075 & & & & \\
\hline$<0,075$ & & & & \\
\hline
\end{tabular}

Figura 13: Análise visual da degradação granulométrica.

\subsection{Avaliação da permeabilidade em cilindro de pequena dimensão}

A Figura 14 mostra as curvas resultantes dos ensaios de permeabilidade. Percebe-se a variação da velocidade de descarga de acordo com o gradiente hidráulico para cada amostra. Na Tabela 8 é apresentado um resumo destes resultados, bem como o coeficiente $\mathrm{R}^{2}$.

A partir da análise da Tabela 8 percebe-se que quanto maior o índice FI do material, menor a velocidade de descarga. Para um lastro altamente colmatado, amostra 4, a velocidade sofreu uma redução de 99,9\% quando comparada ao lastro limpo representado pela amostra 1. Tais resultados condizem com aqueles apresentados por SCHMIDT et al. [7] dado que a velocidade da amostra com FI $\geq 40$ atingiu valores próximos aqueles verificados para areia. Observa-se ainda, que para a amostra 4 a curva da Figura 14, apresenta-se praticamente linear, outra característica similar àquelas verificadas em ensaios com areia.

Em relação às amostras que apresentaram índice FI < 10 (amostras 1 e 2), nota-se que o coeficiente C indicou permeabilidade satisfatória para a condição de lastro ferroviário. Logo, o valor limite de FI igual a 10 confirma-se como balizador para definir a condição de colmatação e permeabilidade do lastro. As amostras com coeficiente FI > 10, classificadas, portanto, como lastro colmatado, mostraram-se inadequadas em relação à drenabilidade da via férrea, evidenciando que o excesso de finos é prejudicial para uma drenagem satisfatória. 


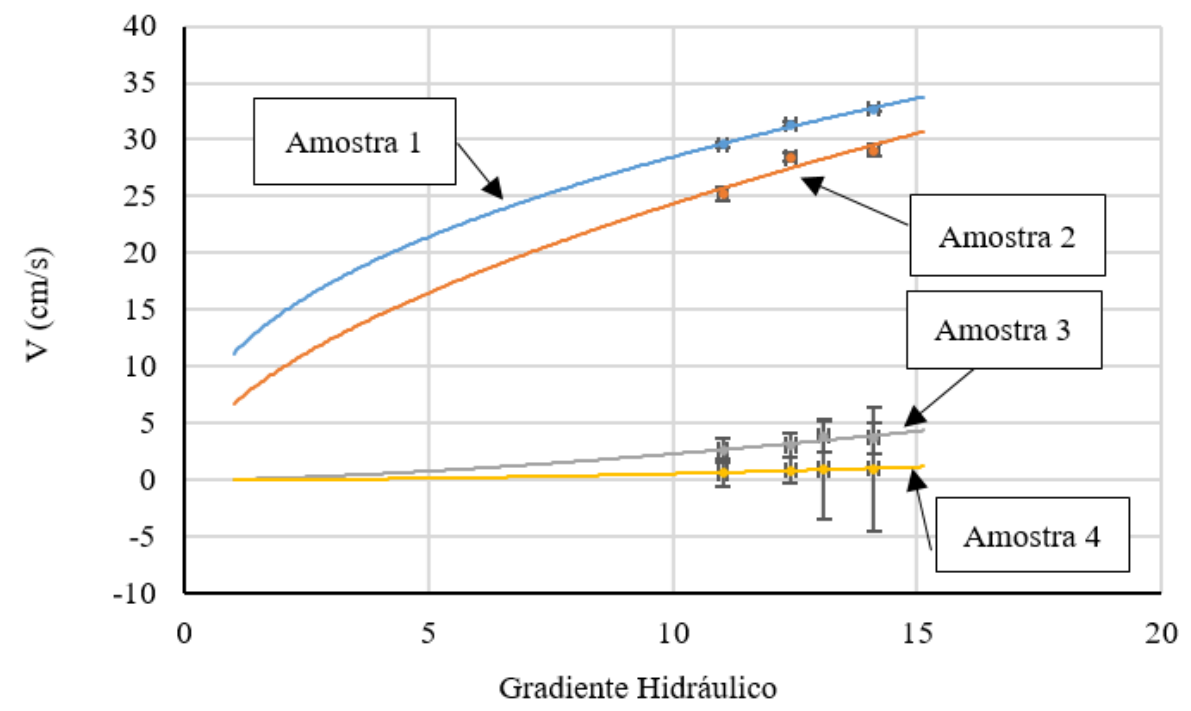

Figura 14: Relação entre a velocidade de descarga e o gradiente hidráulico para as amostras 1, 2, 3 e 4.

Tabela 8: Resumo dos resultados dos ensaios de permeabilidade.

\begin{tabular}{c|c|c|c|c|c}
\hline AMOSTRA & $\mathbf{F I}(\%)$ & $\begin{array}{c}\mathbf{V} \text { em i=1 } \\
(\mathbf{c m} / \mathbf{s})\end{array}$ & $\begin{array}{c}\text { Coeficiente C } \\
(\mathbf{c m} / \mathbf{s})\end{array}$ & Expoente $\mathbf{n}$ & $\mathbf{R}^{\mathbf{2}}$ \\
\hline 1 & 0 & 11,06 & 11,06 & 0,411 & 0,987 \\
\hline 2 & 6,1 & 6,68 & 6,68 & 0,561 & 0,846 \\
\hline 3 & 33,3 & 0,0668 & 0,0668 & 1,54 & 0,83 \\
\hline 4 & 45,9 & 0,0093 & 0,0093 & 1,79 & 0,93 \\
\hline
\end{tabular}

\section{CONCLUSÕES}

Em relação à caracterização do agregado para utilização em lastros ferroviário na região do Triângulo Mineiro, conclui-se que o material se mostrou adequado, uma vez que os ensaios de maior relevância para este fim, como a sanidade e a abrasão Los Angeles, indicaram resistência elevada à degradação e à ação de agentes climáticos.

A partir dos resultados dos ensaios de Single Particle Crushing pode-se dizer que a resistência do agregado é influenciada pelo tamanho de suas partículas, sendo que quanto menor o grão, maior a sua resistência. Além disso, a relação entre a probabilidade de sobrevivência e a tensão de tração de ruptura, para partículas maiores, é melhor representada por uma linha de tendência linear.

A menor resistência das partículas de maior dimensão pode explicar a maior degradação verificada para a fração de $19,1 \mathrm{~mm}$ que contribuiu para o acréscimo de finos na estrutura, mesmo que os grãos maiores não fossem reduzidos por completo. Essa formação de partículas finas mostrou-se responsável pelo fenômeno de colmatação e torna-se elemento nocivo no que tange a drenagem do lastro ferroviário.

Para uma distribuição granulométrica característica de lastro altamente colmatado, notou-se que a velocidade de descarga sofreu uma redução de até $99,9 \%$ quando comparada ao lastro limpo. Em relação às amostras que apresentaram índice FI < 10, o coeficiente C indicou permeabilidade satisfatória para a condição de lastro ferroviário. Logo, o valor limite de FI igual a 10 confirma-se como balizador para definir a condição de colmatação e permeabilidade do lastro. Nesse cenário, a principal conclusão desse trabalho é que lastros colmatados e altamente colmatados comprometem a drenabilidade da estrutura. Assim, a principal recomendação desse estudo é que a avaliação do índice FI e das características de resistência à degradação dos agregados destinados às camadas de lastro ferroviário sejam considerados pelos projetistas nos casos de implantação de uma nova estrutura ou na manutenção de ferrovias já em operação.

\section{AGRADECIMENTOS}

Agradecemos à Fundação de Amparo à Pesquisa do Estado de Mina Gerais (FAPEMIG). 


\section{BIBLIOGRAFIA}

[1] MERHEB, A.H.M., Análise mecânica do lastro ferroviário por meio de ensaios triaxiais cíclicos, Tese de M.Sc., Escola Politécnica/USP, São Paulo, SP, Brasil, 2014.

[2] ESVELD, C., Modern railway track, 2 ed., The Netherlands, MRT-Productions, 2001.

[3] INDRARATNA, B., SALIM, W., RUJIKIATKAMJORN, C., Advanced rail geotechnology ballested track, 1 ed., London, Taylor \& Francis Group, 2011.

[4] COSTA, R.C.da, Proposição de dispositivo de medidas "in situ" para avaliação do comportamento mecânico de lastro ferroviário: Estudo de caso na Estrada de Ferro Carajás, Tese de M.Sc., Escola Politécnica/USP, São Paulo, SP, Brasil, 2016.

[5] BRINA, H.L., Estradas de ferro, 2 ed., Belo Horizonte, Editora UFMG, 1988.

[6] WENTY, R., Railway ballast and its maintenance, In: Plasser \& Theurer, Adelaide, 2009.

[7] SCHMIDT, S., SHAH, S., MOAVENI, M., et al., "Railway Ballast Permeability and Cleaning Considerations", Transportation Research Record, v. 2607, 1, pp. 24-32, Jan. 2017.

[8] LEKARP, F., ISACSSON, U., DAWSON, A., "State of the art. I: Resilient Response of Unbound Aggregates", Journal of Transportation Engineering, v. 126, 1, pp. 66-75, Jan. Feb. 2000.

[9] PIRES, J., COSTA, R., BERNUCCI, L., MOTTA, R., et al., "Degradação do lastro ferroviário - principais aspectos e estudos de caso", Transportes, v. 25, n. 3, pp. 62-74, Out. 2017.

[10] SELIG, E.T., WATERS, J.M., Track geotechnology and substructure management, London, Editora Thomas Telford, 1994.

[11] INDRARATNA, B., SALIM, W., "Deformation and Degradation Mechanics of Recycled Ballast Stabilised with Geosynthetics", Soils and Foundations, v. 43, n. 4, pp. 35-46, Aug. 2003.

[12] WNEK, M.A., TUTUMLUER, E., MOAVENI, M., et al., "Investigation of Aggregate Properties Influencing Railroad Ballast Performance", Transportation Research Record, v. 2374, 1, pp. 180-189, Jan. 2013.

[13] DEPARTAMENTO NACIONAL DE INFRAESTRUTURA DE TRANSPORTES, Manual de custos de infraestrutura de transportes - Volume 10 - Conteúdo 09 - Ferrovias, 1 ed., Brasília, DNIT, 2017.

[14] LIM, W.L., Mechanics of railway ballast behaviour, Tese de D.Sc., The University of Nottingham, Nottingham, Inglaterra, 2004.

[15] AMERICAN SOCIETY FOR TESTING AND MATERIALS, C 136: Standard test method for sieve analysis of fine and coarse aggregates, West Conshohocken, 2001.

[16] ASSOCIAÇÃO BRASILEIRA DE NORMAS TÉCNICAS, NBR 5564: Via férrea - Lastro ferroviário Requisitos e métodos de ensaio, Rio de Janeiro, 2011.

[17] AMERICAN SOCIETY FOR TESTING AND MATERIALS, C 88: Standard test method for soundness of aggregates by use of sodium sulfate or magnesium sulfate, West Conshohocken, 1999.

[18] AMERICAN SOCIETY FOR TESTING AND MATERIALS, C 127: Standard test method for density, relative density (specific gravity) and absorption of coarse Aggregate, West Conshohocken, 2001.

[19] ASSOCIAÇÃO BRASILEIRA DE NORMAS TÉCNICAS, NBR NM 45: Agregados - Determinação da massa unitária e do volume de vazios, Rio de Janeiro, 2006.

[20] AMERICAN SOCIETY FOR TESTING AND MATERIALS, C 535: Standard test method for resistance to degradation of large-size coarse aggregate by abrasion and impact in the Los Angeles Machine, West Conshohocken, 2003.

[21] VIZCARRA, G.O.C., Efeito da granulometria no comportamento mecânico de lastro ferroviário, Tese de D.Sc., Departamento de Engenharia Civil/PUC do Rio de Janeiro, Rio de Janeiro, RJ, Brasil, 2015.

[22] ICSD - INORGANIC CRYSTAL STRUCTURE DATABASE, http://bdec.dotlib.com.br/ cliente/login. Acessado em outubro de 2018.

[23] RAYMOND, G. P., "Railroad Ballast Prescription: State-of-the-Art.", Journal of Geotechnical Engineering Division, ASCE, v. 105, pp 305-322.

\section{ORCID}

Larissa Rodrigues Dutra

https://orcid.org/0000-0003-1588-9466

Rodrigo Pires Leandro

https://orcid.org/0000-0003-4244-5692 